\title{
Cloning and Characterization of Benzoate Catabolic Genes in the Gram-Positive Polychlorinated Biphenyl Degrader Rhodococcus sp. Strain RHA1
}

\author{
WATARU KITAGAWA, KEISUKE MIYAUCHI, EIJI MASAI, AND MASAO FUKUDA* \\ Department of Bioengineering, Nagaoka University of Technology, Nagaoka, Niigata 940-2188, Japan
}

Received 9 April 2001/Accepted 22 August 2001

\begin{abstract}
Benzoate catabolism is thought to play a key role in aerobic bacterial degradation of biphenyl and polychlorinated biphenyls (PCBs). Benzoate catabolic genes were cloned from a PCB degrader, Rhodococcus sp. strain RHA1, by using PCR amplification and temporal temperature gradient electrophoresis separation. A nucleotide sequence determination revealed that the deduced amino acid sequences encoded by the RHA1 benzoate catabolic genes, ben $A B C D K$, exhibit 33 to $65 \%$ identity with those of Acinetobacter sp. strain ADP1. The gene organization of the RHA1 benABCDK genes differs from that of ADP1. The RHA1 benABCDK region was localized on the chromosome, in contrast to the biphenyl catabolic genes, which are located on linear plasmids. Escherichia coli cells containing RHA1 benABCD transformed benzoate to catechol via 2-hydro-1,2-dihydroxybenzoate. They transformed neither 2 - nor 4-chlorobenzoates but did transform 3-chlorobenzoate. The RHA1 ben $A$ gene was inactivated by insertion of a thiostrepton resistance gene. The resultant mutant strain, RBD169, neither grew on benzoate nor transformed benzoate, and it did not transform 3-chlorobenzoate. It did, however, exhibit diminished growth on biphenyl and growth repression in the presence of a high concentration of biphenyl $(13 \mathrm{mM})$. These results indicate that the cloned ben $A B C D$ genes could play an essential role not only in benzoate catabolism but also in biphenyl catabolism in RHA1. Six rhodococcal benzoate degraders were found to have homologs of RHA1 benABC. In contrast, two rhodococcal strains that cannot transform benzoate were found not to have RHA1 ben $A B C$ homologs, suggesting that many Rhodococcus strains contain benzoate catabolic genes similar to RHA1 benABC.
\end{abstract}

Polychlorinated biphenyls (PCBs) are xenobiotic compounds that cause serious environmental problems in the world. The use of microorganisms is expected to be an effective tool for remediation of polluted environments, and many PCBdegrading microorganisms have been described previously (1, 9, 15, 17, 21). Rhodococcus sp. strain RHA1 is a gram-positive bacterium that efficiently degrades PCBs $(29,30)$. A variety of RHA1 genes involved in the metabolism of biphenyl and PCBs have been characterized $(12,19,20,34)$, including the $b p h A C B$ and $b p h D E F$ gene clusters. It is thought that PCBs are metabolized through a biphenyl pathway (Fig. 1) encoded by the $b p h$ genes. Benzoate and chlorobenzoates are intermediate metabolites of biphenyl and PCB degradation. Chlorobenzoate accumulation is often observed during PCB degradation $(13,18$, 32). Benzoate metabolism appears to be a key element of PCB degradation, and attempts have been made to improve PCB degradation activity by introducing chlorobenzoate metabolic genes $(27,28)$. Although the benzoate metabolic pathway enzymes and genes have been well characterized thus far $(6,10$, 24), the role of benzoate metabolism in biphenyl and PCB degradation has been poorly documented. In the present study, we isolated and characterized the genes for benzoate metabolism in strain RHA1 and a benzoate metabolism insertion mutant of this strain in order to examine the significance of benzoate metabolism in biphenyl and PCB degradation. We

\footnotetext{
* Corresponding author. Mailing address: Department of Bioengineering, Nagaoka University of Technology, Kamitomioka, Nagaoka, Niigata, 940-2188, Japan. Phone: 81-258-47-9405. Fax: 81-258-47-9450. E-mail: masao@vos.nagaokaut.ac.jp.
}

also describe here for the first time the features of benzoate catabolic genes of gram-positive bacteria.

\section{MATERIALS AND METHODS}

Bacterial strains, plasmids, and culture conditions. The plasmids and bacterial strains used in this study are listed in Table 1. Rhodococcus strains were grown in Luria-Bertani (LB) medium and W minimal medium (20) with biphenyl or benzoate at $30^{\circ} \mathrm{C}$. Escherichia coli JM109 was used as a host strain.

DNA manipulations and analysis. All of the DNA techniques used, including isolation of total DNA, gene cloning, sequencing, Southern hybridization, electrotransformation (electroporation), pulsed-field gel electrophoresis, and computer analysis have been described previously $(19,20,34)$. The following primer sequences were used to amplify the ben $A$ gene sequence in strain RHA1: forward primer, 5'-TGCASSTWTCACGGSTGG-3'; and reverse primer, 5'-CTCGACT CCGAGCTTCCAGTT-3' (16).

Detection of gene products. The gene products expressed in E. coli JM109 were detected by sodium dodecyl sulfate-polyacrylamide gel electrophoresis (SDS-PAGE) as described previously (19).

Assays for benzoate conversion activity. (i) Growing cell assay. E. coli cells grown in LB medium were inoculated into $10 \mathrm{ml}$ of fresh LB medium containing $500 \mu \mathrm{M}$ benzoate and $1 \mathrm{mM}$ IPTG (isopropyl- $\beta$-D-thiogalactopyranoside) to an optical density at $660 \mathrm{~nm}\left(\mathrm{OD}_{660}\right)$ of 0.1 . After incubation with shaking for $6 \mathrm{~h}$ at $30^{\circ} \mathrm{C}$, a $1-\mathrm{ml}$ aliquot was withdrawn, and cells were removed by centrifugation $(10,000 \times g, 10 \mathrm{~min})$. The supernatant was filtered through a membrane filter (pore size, $0.45 \mu \mathrm{m}$; Advantec, Tokyo, Japan), and the filtrate was analyzed by high-performance liquid chromatography (HPLC). The HPLC analysis was performed with an Alliance 2690 system (Waters, Randolph, Mass.) and a TSKgel ODS-80TM column (inside diameter, $6 \mathrm{~mm}$; length, $150 \mathrm{~mm}$; Tosoh, Tokyo, Japan) at room temperature. The mobile phase was a mixture of water $(50.0 \%)$, acetonitrile $(49.5 \%)$, and phosphate $(0.5 \%)$, and the total flow rate was 1.3 $\mathrm{ml} / \mathrm{min}$. Benzoate and metabolites were detected with a UV spectrophotometric detector at $229 \mathrm{~nm}$ for benzoate, $254 \mathrm{~nm}$ for 2-hydro-1,2-dihydroxybenzoate (DHB), and $280 \mathrm{~nm}$ for catechol. Gas chromatography-mass spectrometry (GCMS) analysis was performed as described previously (29).

(ii) Resting cell assay. $E$. coli cells grown in LB medium were inoculated into $10 \mathrm{ml}$ of $\mathrm{W}$ minimal medium containing $500 \mu \mathrm{M}$ benzoate and $1 \mathrm{mM}$ IPTG to an 

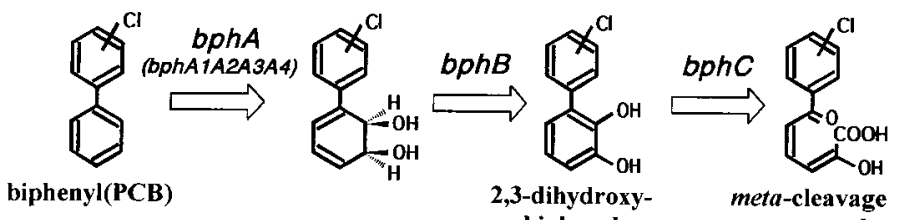

biphenyl compound

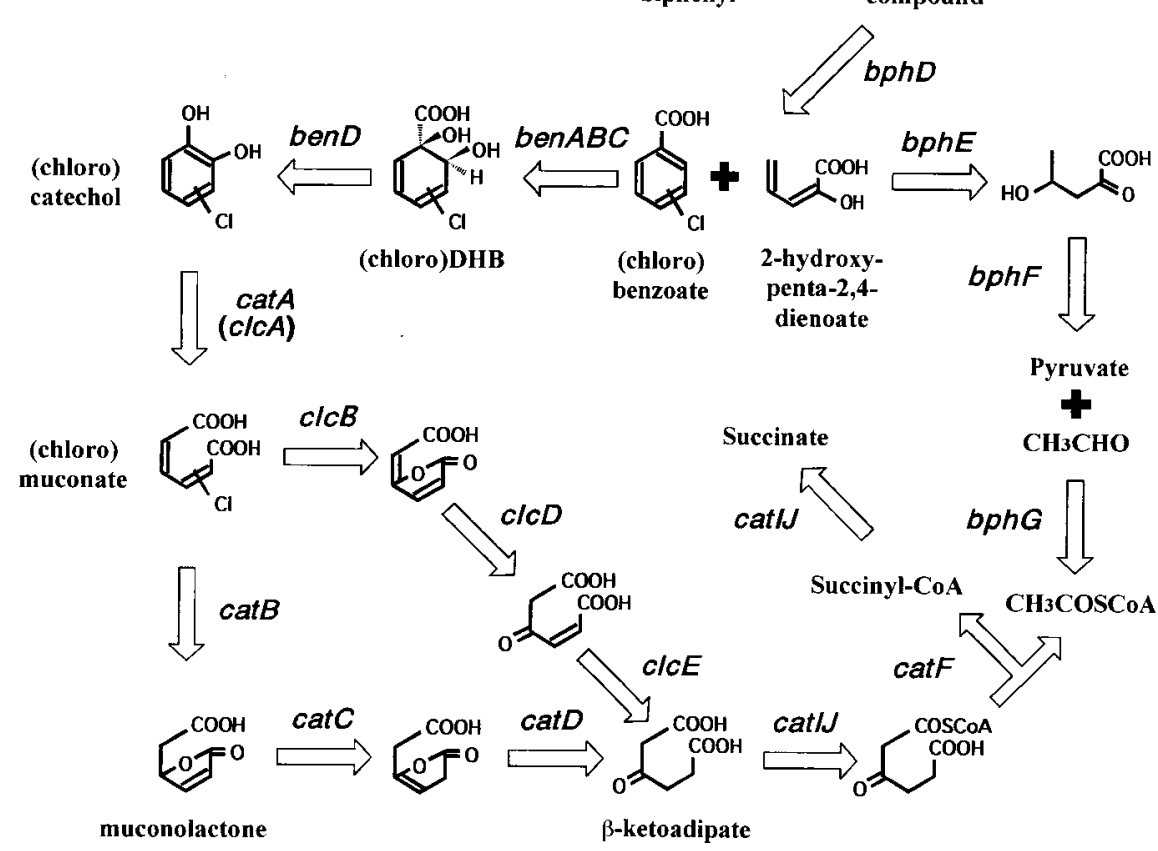

FIG. 1. Proposed pathway for aerobic bacterial degradation of biphenyl and PCBs. bphA, biphenyl dioxygenase complex composed of large and small terminal dioxygenase subunits encoded by $b p h A 1$ and $b p h A 2$, respectively, ferredoxin encoded by $b p h A 3$, and ferredoxin reductase encoded by $b p h A 4 ; b p h B, 2,3$-dihydroxy-1-phenylcyclohexa-4,6-diene dehydrogenase (dihydrodiol dehydrogenase); $b p h C, 2,3$-dihydroxybiphenyl 1,2-dioxygenase; $b p h D, 2$-hydroxy-6-oxo-6-phenylhexa-2,4-dienoate hydrolase; $b p h E$, 2-hydroxypenta-2,4-dienoate hydratase; $b p h F, 4$-hydroxy-2-oxovalerate aldolase; $b p h G$, acetaldehyde dehydrogenase; ben $A B C$, benzoate dioxygenase complex composed of large and small subunits encoded by ben $A$ and ben $B$, respectively, and electron transfer conponent encoded by ben $C$; ben D, DHB dehydrogenase; cat $A$ (clc $A$ ), (chloro)catechol 1,2-dioxygenase; $\operatorname{cat} B$, muconate cycloisomerase; $\operatorname{cat} C$, muconolactone isomerase; $\operatorname{cat} D, \beta$-ketoadipate enol-lactone hydrolase; $\operatorname{clc} B$, chloromuconate cycloisomerase; $c l c D$, dienelactone hydrolase; $c l c E$, maleylacetate reductase; catIJ, $\beta$-ketoadipate succinyl coenzyme A transferase; $c a t F$, $\beta$-ketoadipyl coenzyme A thiolase.

$\mathrm{OD}_{660}$ of 1.0 and were incubated with shaking for $6 \mathrm{~h}$ at $30^{\circ} \mathrm{C}$. In the case of RHA1 and the RHA1 mutant strain, cells grown in LB medium were resuspended in $\mathrm{W}$ minimal medium containing $1 \mathrm{mM}$ benzoate and were incubated with shaking for $1 \mathrm{~h} \mathrm{at} 30^{\circ} \mathrm{C}$. Cells were then resuspended in $10 \mathrm{ml}$ of W minimal medium containing $500 \mu \mathrm{M}$ benzoate at an $\mathrm{OD}_{660}$ of 1.0 and incubated with shaking for $30 \mathrm{~min}$ at $30^{\circ} \mathrm{C}$. At selected times, $1-\mathrm{ml}$ aliquots were centrifuged and filtered and then subjected to HPLC and GC-MS analysis as described above.

(iii) Crude cell assay. E. coli cells harvested from $50 \mathrm{ml}$ of LB medium containing $1 \mathrm{mM}$ IPTG were washed and resuspended in $1 \mathrm{ml}$ of sample buffer (20 mM potassium phosphate buffer [pH 7.5] containing $15 \%$ glycerol, $10 \%$ ethanol, and $2 \mathrm{mM}$ dithiothreitol). The cells in the suspension were disrupted by sonication. After centrifugation $(20,000 \times g, 30 \mathrm{~min})$, the supernatants were used as crude extracts. The standard assay was carried out at $30^{\circ} \mathrm{C}$, and the assay mixture contained $250 \mu \mathrm{l}$ of protein sample and $4,750 \mu \mathrm{l}$ of $100 \mathrm{mM}$ sodium morpholinoethanesulufonic acid (MES) buffer ( $\mathrm{pH}$ 6.5) supplemented with 0.1 $\mathrm{mM} \mathrm{Fe}\left(\mathrm{NH}_{4}\right)_{2}\left(\mathrm{SO}_{4}\right)_{2}, 2 \mu \mathrm{M}$ flavin adenine dinucleotide, $2 \mathrm{mM} \mathrm{NADH}$, and 1 $\mathrm{mM}$ benzoate. At selected times, the reactions were terminated by adding equal volumes of methanol. The samples were centrifuged and filtered and then subjected to HPLC and GC-MS analysis as described above.

Assay for benzoate transformation velocity. RHA1 and the benK mutant strain, RBD201, were grown in LB medium, and the cells were incubated at $30^{\circ} \mathrm{C}$ with shaking in a series of $\mathrm{W}$ minimal medium preparations containing $100 \mu \mathrm{M}$ benzoate whose $\mathrm{pH}$ values were adjusted to 6.2, 7.3, and 8.4. Prior to incubation, the $\mathrm{OD}_{660}$ was adjusted to 0.1 . At selected times, 1 -ml aliquots were subjected to HPLC analysis to determine the remaining amounts of benzoate as described above.
Primer extension analysis. Total RNA was prepared from RHA1 cells grown at $30^{\circ} \mathrm{C}$ in $\mathrm{W}$ minimal medium supplemented with $10 \mathrm{mM}$ benzoate as described by Ausubel et al. (2). To map the $5^{\prime}$ end of the transcript of benA, automated fluorescent primer extension analysis with a Cy5 fluorescently labeled primer and an ALFexpress DNA sequencer (Amersham Pharmacia Biotech) was performed essentially as described by Myöhänen and Wahlfors (22).

Gene disruption. To disrupt the benA gene, a 1.1-kb $N s p V-A p a \mathrm{I}$ fragment containing the internal region of ben $A$ was inserted into pUC-tsr, which was composed of pUC19 and the thiostrepton resistance gene (tsr). The resulting plasmid, pDA-tsr, was introduced into RHA1 cells by electroporation. Transformants were selected on LB agar plates containing $20 \mu \mathrm{g}$ of thiostrepton per ml and were subjected to a Southern hybridization analysis in order to examine insertion of pDA-tsr into the chromosomal benA gene by single crossover. In the case of benK gene disruption, a 774-bp BglII-MluI fragment containing the internal region of benK was inserted into pBS-tsr, which was composed of pBluescript II and $t s r$. Insertion of the resulting plasmid, pDK-tsr, into the chromosomal benK gene was carried out as described above.

Plasmid pBsRG6 was used as a source of the thiostrepton resistance gene (tsr) fragment and was a gift from R. van der Geize (University of Groningen, Groningen, The Netherlands).

To perform benA gene complementation in RBD169, pK4BA was constructed by inserting a 1.9-kb KpnI-BglII fragment containing intact benA into an E. coli-Rhodococcus shuttle vector, pK4, and it was introduced into RBD169 by electroporation. A transformant, RBD169(pK4BA), was isolated on an LB agar plate containing $50 \mu \mathrm{g}$ of kanamycin per $\mathrm{ml}$, and the plasmid DNA was recovered to confirm the presence of pK4BA. RBD169(pK4BA) cells grown in LB medium 
TABLE 1. Strains and plasmids used in this study

\begin{tabular}{|c|c|c|}
\hline Strain or plasmid & Relevant characteristic(s) ${ }^{a}$ & Reference or origin \\
\hline \multicolumn{3}{|l|}{ Strains } \\
\hline Rhodococcus sp. strain RHA1 & PCB degrader, $\mathrm{Ben}^{+}$ & 29 \\
\hline Rhodococcus sp. strain RBD169 & benA mutant of strain RHA1, Ben ${ }^{-}$ & This study \\
\hline Rhodococcus sp. strain RBD201 & ben $K$ mutant of strain RHA1, Ben ${ }^{+}$ & This study \\
\hline R. erythropolis NY05 & PCB degrader, $\mathrm{Ben}^{+}$ & 25 \\
\hline R. erythropolis IAM1399 (= ATCC 15963) & Wild type, Ben ${ }^{+}$ & IAM culture collection ${ }^{b}$ \\
\hline R. rhodochrous IAM12121 (= ATCC 1273) & Wild type, Ben ${ }^{+}$ & IAM culture collection \\
\hline R. rhodochrous IAM12123 (= ATCC 1276) & Wild type, Ben $^{+}$ & IAM culture collection \\
\hline R. rhodochrous IAM12124 (= ATCC 15906) & Wild type, Ben $^{+}$ & IAM culture collection \\
\hline $\begin{array}{l}\text { R. roseus (R. rhodochrous) IAM12127 } \\
\text { (= ATCC 4004) }\end{array}$ & Wild type, Ben ${ }^{+}$ & IAM culture collection \\
\hline R. erythropolis IAM12122 (= ATCC 1277) & Wild type, Ben ${ }^{-}$ & IAM culture collection \\
\hline R. erythropolis IAM1484 (= ATCC 15961) & Wild type, Ben ${ }^{-}$ & IAM culture collection \\
\hline \multicolumn{3}{|l|}{ Plasmids $\mathrm{T}$ - } \\
\hline pBsRG6 & Cloning vector, $\mathrm{Ap}^{\mathrm{r}} \mathrm{Ts}^{\mathrm{r}}$ & R. van der Geize \\
\hline pUC19 & Cloning vector, $\mathrm{Ap}^{\mathrm{r}}$ & 35 \\
\hline pUC-tsr & pUC19 with insertion of $t s r$ gene from pBsRG6, $\mathrm{Ap}^{\mathrm{r}} \mathrm{Ts}^{\mathrm{r}}$ & This study \\
\hline pBluescript II KS & Cloning vector, $\mathrm{Ap}^{\mathrm{r}}$ & Stratagene \\
\hline pBS-tsr & $\begin{array}{l}\text { pBluescript II KS with insertion of } t s r \text { gene from pUC-tsr, } \\
\mathrm{Ap}^{\mathrm{r}} \mathrm{Ts}^{\mathrm{r}}\end{array}$ & This study \\
\hline pK4 & Rhocococcus-E. coli shuttle vector, $\mathrm{Km}^{\mathrm{r}}$ & 11 \\
\hline pBK4 & $\begin{array}{l}\text { pBluescript II KS with 4.4-kb SmaI fragment of RHA1 carrying } \\
\text { ben } A B C D \text {, direction of ben } A B C D \text { is identical to that of the } \\
\text { lac promoter of pBluescript II KS }\end{array}$ & This study \\
\hline pBK11 & Deletion clone of pBK4 carrying ben $A B C$ & This study \\
\hline pDA-tsr & $\begin{array}{l}\text { ben } A \text { disruption plasmid, pUC-tsr with 1.1-kb Nsp V-ApaI benA } \\
\text { internal fragment }\end{array}$ & This study \\
\hline pDK-tsr & $\begin{array}{l}\text { benK disruption plasmid, pBS-tsr with 774-bp BglII-MluI benK } \\
\text { internal fragment }\end{array}$ & This study \\
\hline pK4BA & $\begin{array}{l}\text { pK4 with } 1.9-\mathrm{kb} \text { KpnI-BglII fragment carrying ben } A \text {, } \\
\text { complements the benA mutant }\end{array}$ & This study \\
\hline
\end{tabular}

${ }^{a} \mathrm{Ben}^{+}$, growth on benzoate; Ben ${ }^{-}$, no growth on benzoate; $\mathrm{Ts}^{\mathrm{r}}$, thiostrepton resistance.

${ }^{b}$ IAM, Institute of Applied Microbiology.

were washed and resuspended in $\mathrm{W}$ minimal medium containing $10 \mathrm{mM}$ benzoate. The $\mathrm{OD}_{660}$ was adjusted to 0.02 , and the cell suspension was incubated at $30^{\circ} \mathrm{C}$ with shaking.

Growth of RBD169 on biphenyl was examined by incubating RBD169 cells at $30^{\circ} \mathrm{C}$ with shaking in $\mathrm{W}$ minimal medium containing $3.25,6.5$, or $13 \mathrm{mM}$ biphenyl. Prior to incubation, RBD169 was grown in LB medium, and the $\mathrm{OD}_{660}$ was adjusted to 0.02 .

Nucleotide sequence accession number. The nucleotide sequence determined in this study has been deposited in the DDBJ, EMBL, and GenBank databases under accession no. AB055706.

\section{RESULTS}

Cloning of benzoate dioxygenase genes. To clone benzoate dioxygenase genes, PCR was performed with the primer sequences conserved in aromatic ring hydroxylation dioxygenase genes. The 300-bp fragments amplified from RHA1 total DNA were separated into five PCR products by temporal temperature gradient electrophoresis and extracted from the gel. The nucleotide sequence of each PCR product was determined. Three of the products were found to contain parts of putative new aromatic ring hydroxylation dioxygenase genes in RHA1 (16). One of the PCR products obtained for new genes was similar to benA of Acinetobacter sp. strain ADP1 (23) and was used as a probe to perform colony hybridization of the RHA1 cosmid gene library in E. coli. Thus, we obtained cosmid clone pK4BK2, which gave a PCR product whose sequence completely matched the probe sequence. The nucleotide sequence of the 6,957-bp (EcoRI-BglII) region in pK4BK2 containing the probe sequence was determined, which revealed five open reading frames that exhibited similarity to the ben $A B C D$ and ben $K$ genes of Acinetobacter sp. strain ADP1 (23). These open reading frames were designated ben $A B C D K$ (Fig. 2). As shown in Table 2, the deduced amino acid sequences of the RHA1 ben $A B C D$ gene products (BenABCD) exhibited 53 to $69 \%$ identity with the amino acid sequences of BenABCD of ADP1 and Pseudomonas putida PRS2000. In addition, BenK of RHA1 exhibited 33 and $38 \%$ identity with BenK of ADP1 and BenK of PRS2000, respectively $(7,23)$. The sizes of the corresponding genes of RHA1 and ADP1 were almost the same, except for benC. The RHA1 benC gene was 537 bp (encoding 179 amino acids) longer than the ADP1 ben $C$ gene. The similarities between RHA1 BenC and ADP1 BenC or other related proteins occurred from the amino termini to the carboxyl termini of the proteins, except for the extra carboxyl-terminal sequence of RHA1 BenC.

Expression of ben $A B C D$ genes in $\boldsymbol{E}$. coli. To identify the gene products, ben $A B C D$ was subcloned from $\mathrm{pK} 4 \mathrm{BK} 2$ to construct pBK4 (Fig. 2). The genes in pBK4 were expressed under control of the lac promoter in E. coli JM109, and the proteins were separated by SDS-PAGE (Fig. 3). Four products, at 50.0, 22.8, 56.4 , and $28.4 \mathrm{kDa}$, were observed (lane 3), and these molecular masses were in good agreement with those calculated from the deduced amino acid sequences of BenA (51.7 kDa), BenB (20.0 kDa), BenC (56.0 kDa), and BenD (27.8 kDa), respectively.

Transformation of benzoate by ben $A B C D$ gene products was 


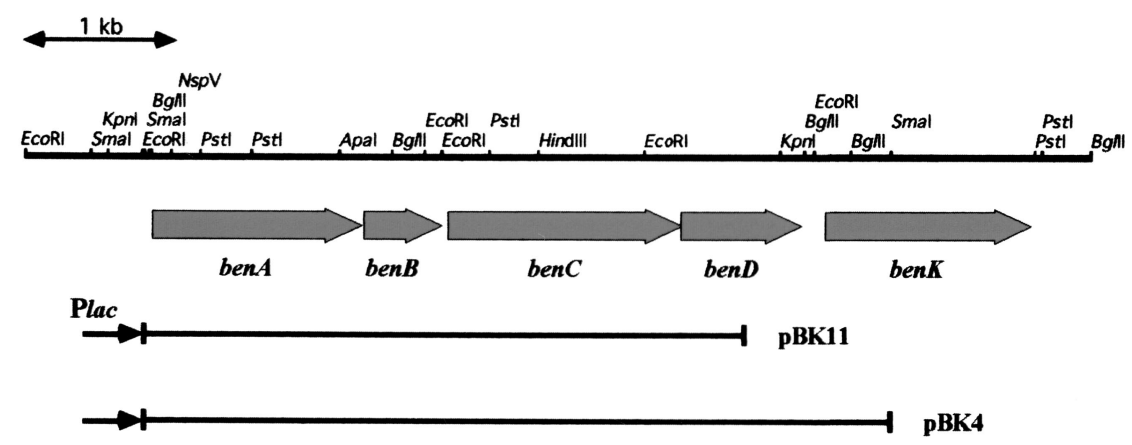

FIG. 2. Organization of the ben genes in Rhodococcus sp. strain RHA1. The thick arrows indicate open reading frames corresponding to ben $A$, ben $B$, ben $C$, ben $D$, and benK. Fragments cloned in pBluescript II are indicated at the bottom. pBK4 and pBK11 contain ben $A B C D$ and ben $A B C$, respectively. The thin arrows indicate the direction of transcription from the adjacent lac promoter of the vector plasmid.

examined in E. coli JM109, which can transform neither benzoate nor its metabolite, DHB. It is thought that e ben $A B C$ and ben $D$ encode a benzoate dioxygenase and a DHB dehydrogenase, respectively, which catalyze conversion of benzoate to DHB and conversion of DHB to catechol (Fig. 1). None of the crude cell extracts of $E$. coli cells containing pBK4, which contained ben $A B C$, or $E$. coli cells containing pBK11, which contained ben $A B C D$ (Fig. 2), transformed benzoate even in the presence of flavin adenine dinucleotide and NADH. No transformation was detected even in a resting cell assay. Therefore, a growing cell assay was performed as described in Materials and Methods. HPLC analysis showed that transformation of benzoate to some metabolite occurred in each culture containing cells harboring either pBK4 or pBK11. Each metabolite was extracted and analyzed by GC-MS. The metabolites from the cultures of pBK4- and pBK11-containing cells were identified as catechol and DHB, respectively (data not shown). Transformation of chlorobenzoates was also examined with $E$. coli cells containing pBK11. The cells were grown in LB medium containing either $500 \mu \mathrm{M}$ benzoate or $500 \mu \mathrm{M}$ chlorobenzoates. During the $6 \mathrm{~h}$ of growth, $55 \%$ of the benzoate and $13 \%$ of the 3 -chlorobenzoate were transformed, while transformation of 2- and 4-chlorobenzoates was not observed. In the case of the RHA1 resting cell assay, the cells were induced in $\mathrm{W}$ minimal medium containing $1 \mathrm{mM}$ benzoate. During 30 min of incubation of the induced cells in W minimal medium containing each substrate at a concentration of 500 $\mu \mathrm{M}, 62 \%$ of the benzoate and $32 \%$ of the 3 -chlorobenzoate were transformed. No transformation of 2- and 4-chlorobenzoates was observed. These results suggest that the RHA1 ben $A B C$ gene product could transform not only benzoate but also 3-chlorobenzoate.

Localization of ben genes on the chromosome. RHA1 contains three linear plasmids, pRHL1 (1,100 kb), pRHL2 (450 $\mathrm{kb})$, and pRHL3 $(330 \mathrm{~kb})$. The primary PCB degradation genes, $b p h A B C$ and $b p h D E F$, are located on pRHL1 and pRHL2, respectively $(19,31)$. Pulsed-field gel electrophoresis and Southern hybridization analysis were performed to localize the ben $A B C$ genes on replicons in RHA1. The ben $A$ gene probe hybridized to the origin of electrophoresis, where chromosomal DNAs remained (data not shown). These results suggest a chromosomal localization for the ben $A B C$ genes.

Primer extension analysis of the ben operon. To map the transcription start site of the benA gene in RHA1, automated fluorescent primer extension analysis was performed. cDNA synthesis was carried out with Cy5-labeled benA-PEX primer (5'-CGAAGATGTGCTTCATCTCG-3'), which is complementary to the bases 132 to $151 \mathrm{bp}$ downstream from the initiation codon of benA. As shown in Fig. 4, the nucleotides located 58 and 66 bp upstream from the ben $A$ start codon were identified as the minor and major transcription start points, respectively, for the benA gene in RHA1 cells grown on benzoate. No transcription start point for ben $A$ was observed in the case of RHA1 cells grown in LB medium. The possible $\sigma 70$ promoter consensus, including -10 and -35 hexamers with the 17-bp optimal spacing between them, was located at the appropriate position for the minor transcription start site.

Disruption of ben $\boldsymbol{A}$ gene in RHA1. To examine if the cloned ben genes are essential for benzoate catabolism in RHA1, the ben $A$ gene was insertionally inactivated by homologous recom-

TABLE 2. Levels of identity between RHA1 ben gene products and representative homologs

\begin{tabular}{|c|c|c|c|c|c|}
\hline \multirow{2}{*}{$\begin{array}{l}\text { RHA1 } \\
\text { protein }\end{array}$} & \multicolumn{5}{|c|}{$\%$ Identity with RHA1 products (deduced amino acid sequence) ${ }^{a}$} \\
\hline & $\begin{array}{l}\text { Acinetobacter } \text { sp. strain ADP1 } \\
\text { (accession no. AF009224) }\end{array}$ & $\begin{array}{c}\text { P. putida PRS2000 } \\
\text { (accession no. AF218267) }\end{array}$ & $\begin{array}{c}\text { P. putida pWW0 } \\
\text { (accession no. M64747) }\end{array}$ & $\begin{array}{l}\text { Burkholderia cepacia 2CBS } \\
\text { (accession no. X79076) }\end{array}$ & $\begin{array}{l}\text { Acinetobacter } \text { sp. strain ADP1 } \\
\text { (accession no. AF071556) }\end{array}$ \\
\hline BenA & $63.4(\mathrm{BenA})$ & 64.1 (BenA) & 65.0 (XylX) & 55.3 (CbdA) & 46.4 (AntA) \\
\hline BenB & 61.8 (BenB) & 69.4 (BenB) & 58.0 (XylY) & 54.8 (CbdB) & 37.2 (AntB) \\
\hline BenC & 52.7 (BenC) & 54.8 (BenC) & 53.9 (Xylz) & 47.7 (CbdC) & 37.5 (AntC) \\
\hline BenD & $58.0(\mathrm{BenD})$ & $65.3(\mathrm{BenD})$ & 63.7 (XylL) & & \\
\hline BenK & 32.9 (BenK) & 38.3 (BenK) & & & \\
\hline
\end{tabular}

${ }^{a}$ Levels of identity were estimated for the longest stretch of identity. 


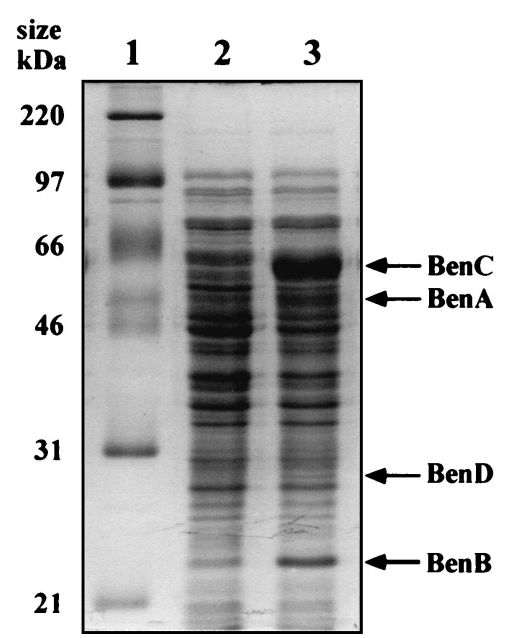

FIG. 3. Expression of ben $A B C D$ genes in E. coli JM109. Cell extracts of $E$. coli transformants grown in the presence of IPTG were subjected to $0.1 \%$ SDS-12\% PAGE. Lane 1, molecular mass marker; lane 2, E. coli JM109(pBluescript II); lane 3, E. coli JM109(pBK4 carrying ben $A B C D)$.

bination (Fig. 5). We constructed plasmid pDA-tsr to inactivate the ben $A$ gene by a single crossover. A single crossover between chromosomal and pDA-tsr ben $A$ sequences was expected to generate tandemly duplicated $\operatorname{ben} A$ sequences, resulting in a vector containing a thiostrepton resistance gene between the sequences (Fig. 5A). Because the ben $A$ gene in pDA-tsr was truncated at both termini, the upstream ben $A$ sequence lacked the carboxyl terminus, and the downstream ben $A$ sequence lacked the amino terminus. As a result, both of the ben $A$ sequences had deletions, and neither of them was functional. pDA-tsr was introduced into RHA1 by electropo- ration, and thiostrepton-resistant transformants were recovered. Southern hybridization analysis of the restriction fragments of total genomic DNA prepared from each transformant was performed to confirm the expected arrangement of duplicated ben $A$ sequences. Figure 5B shows the results obtained with the thiostrepton-resistant transformant, RBD169. Both the ben $A$ and $t s r$ probes hybridized to a single BglII fragment of RBD169, which was $4.9 \mathrm{~kb}$ larger than the RHA1 fragment, indicating that insertion of the entire 4.9-kb pDA-tsr segment into the ben $A$ sequence occurred. RBD169 did not grow on benzoate. In the resting cell assay, RBD169 transformed neither benzoate nor 3-chlorobenzoate. These results indicated that the cloned ben genes were responsible for benzoate metabolism and 3-chlorobenzoate metabolism.

To complement ben $A$ gene deficiency, pK4BA containing an intact ben $A$ gene was introduced into RBD169 by electroporation. Transformant RBD169(pK4BA) grew well on $10 \mathrm{mM}$ benzoate, although its rate of growth was lower than that of the wild type. An RHA1 culture reached an $\mathrm{OD}_{660}$ of 1.9 after $30 \mathrm{~h}$ of incubation, but it took $42 \mathrm{~h}$ for RBD169(pK4BA) to reach the same $\mathrm{OD}_{660}$ (data not shown). These results indicated again that the cloned ben $A$ gene was responsible for benzoate metabolism.

We also isolated ben $K$ gene mutant strain RBD201 by the same method that was used for ben $A$ gene disruption. ben $K$ was expected to encode a benzoate transporter protein. We compared the growth of benK mutant RBD201 with the growth of wild-type strain RHA1 when benzoate was used as the sole source of carbon. However, no significant difference was observed between the growth rates of RBD201 and RHA1. We then compared the rates of transformation of benzoate for RHA1 and RBD201 at different pH values. At pH 6.2, both strains transformed $100 \mu \mathrm{M}$ benzoate at almost the same rate.
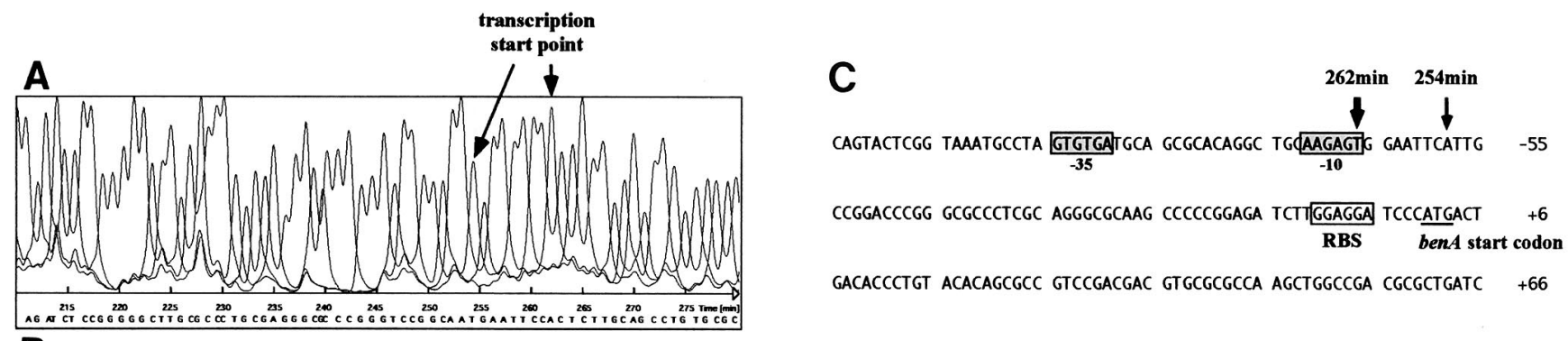
B
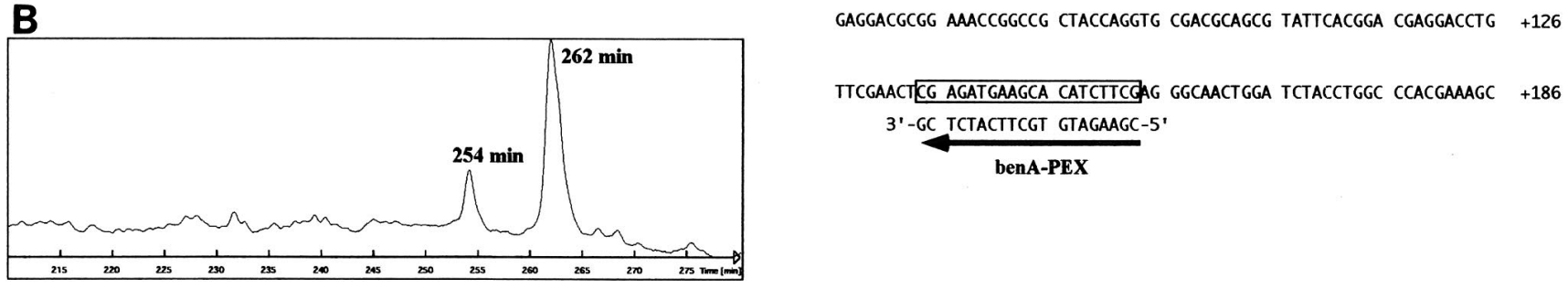

FIG. 4. Automated fluorescent primer extension analysis of the benA transcript produced in RHA1. (A) Nucleotide sequence obtained with cloned benA, the upstream DNA region, and fluorescent primer benA-PEX. The arrow indicates the transcription start point in the genomic sequence. (B) Primer extension product obtained by using RNA from benzoate-grown RHA1 cells as the template and primer benA-PEX. The retention times of the products are indicated. (C) Nucleotide sequence of the upstream region of benA. The vertical arrows indicate transcriptional start points estimated from panels $\mathrm{A}$ and $\mathrm{B}$. The horizontal arrow indicates the position of the benA-PEX primer, whose nucleotide sequence is shown above the arrow. The putative $\sigma 70$ promoter sequence and the deduced ribosome-binding site (RBS) for ben $A$ are enclosed in boxes; the former is also shaded. The start codon of ben $A$ is underlined. 
$\mathbf{A}$

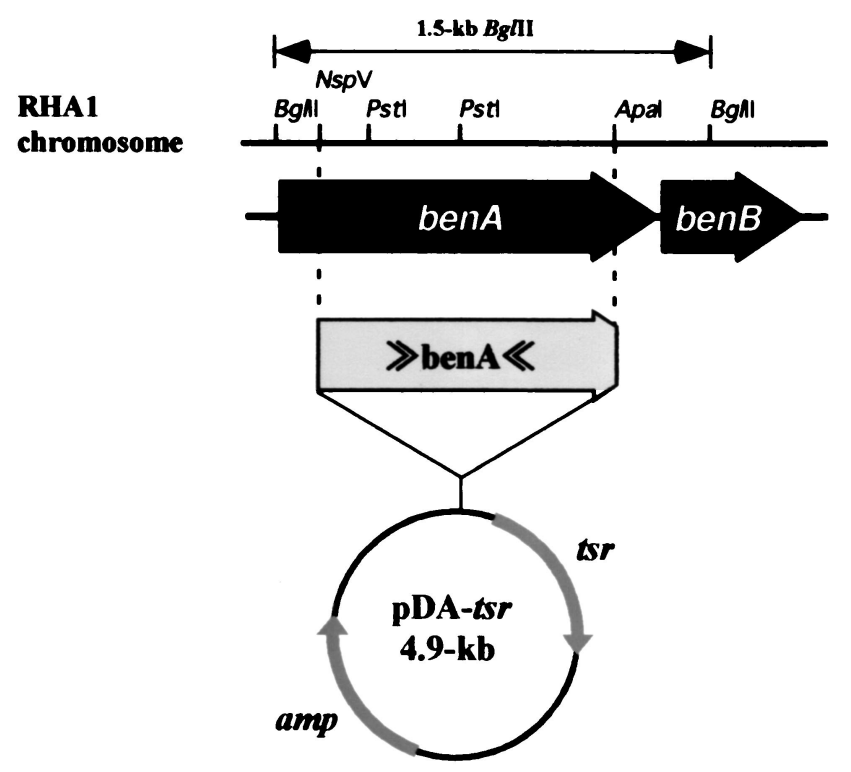

chromosome

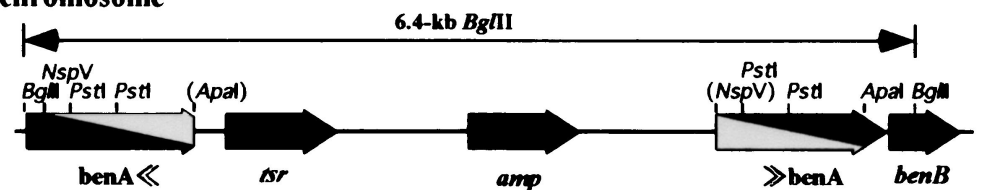

$\mathbf{B}$

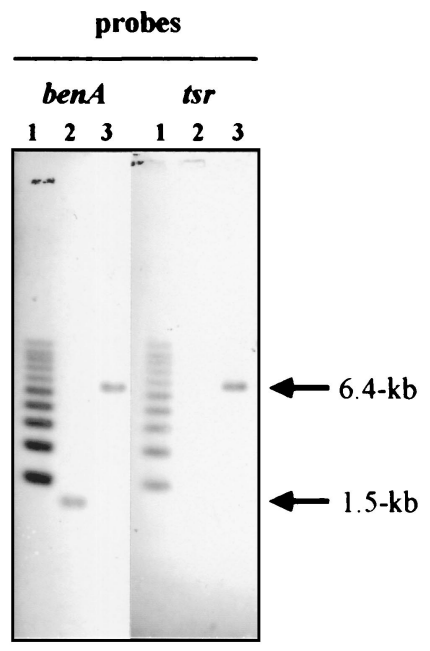

FIG. 5. benA gene disruption in Rhodococcus sp. strain RHA1. (A) Strategy for gene disruption. Disruption of the benA gene was accomplished by a single crossover between the chromosomal ben $A$ gene and the pDA-tsr plasmid containing truncated ben $A$ whose amino and carboxyl termini were deleted. The sizes of $B g l \mathrm{II}$ fragments containing the ben $A$ sequence are indicated. $\gg$ and $\ll$ represent amino-terminal $\left(5^{\prime}\right)$ and carboxylterminal ( $3^{\prime}$ ) deletions, respectively. (B) Southern blot analysis of benA insertion mutant strain RBD169. Lanes 1, 1-kb ladder marker; lanes 2, RHA1 total DNA digested with BglII; lanes 3, RBD169 total DNA digested with BglII. The benA gene fragment (left lanes) and the tsr gene fragment (right lanes) were used as probes.

At pH 7.3, RHA1 transformed benzoate 1.5 -fold more efficiently than RBD201 transformed benzoate, and at $\mathrm{pH} 8.4$, RHA1 transformed benzoate 2-fold more efficiently than RBD201 transformed benzoate (data not shown). These results suggested that the cloned ben $K$ gene plays a role in transport of benzoate. They agreed with the results obtained with a benK mutant of ADP1, in which the role of benK was masked at low $\mathrm{pH}(6)$.

Growth of RBD169 on biphenyl. Because RBD169 is deficient in benzoate metabolism, it is expected to utilize $42 \%$ of biphenyl carbon atoms by metabolizing 2-hydroxypenta-2,4dienoate (containing 5 carbon atoms) produced from biphenyl (containing 12 carbon atoms). When RBD169 was grown on 3.25 or $6.5 \mathrm{mM}$ biphenyl as the sole source of carbon, the maximum $\mathrm{OD}_{660}$ values were 38 and $41 \%$ of those obtained with RHA1 (Fig. 6). For the most part, these values are consistent with the estimated values described above. When RBD169 was grown on $13 \mathrm{mM}$ biphenyl, however, the maximum $\mathrm{OD}_{660}$ was $22 \%$ of the $\mathrm{OD}_{660}$ obtained for RHA1 and was as high as the $\mathrm{OD}_{660}$ when the organism was grown on 6.5 $\mathrm{mM}$ biphenyl. In addition, RBD169 accumulated as much benzoate from $13 \mathrm{mM}$ biphenyl as it accumulated from $6.5 \mathrm{mM}$ biphenyl, suggesting that growth and metabolism of RBD169 might have been inhibited by an excessive amount of benzoate accumulating from biphenyl. When RBD169 was grown on 13 $\mathrm{mM}$ biphenyl, the culture $\mathrm{pH}$ dropped to as low as 5.9. The growth of RHA1 exhibited a greater lag than the growth of RBD169, and the extent of the lag was dependent on the initial amount of biphenyl. These results suggested that growth was inhibited by some metabolite derived from benzoate that was not metabolized in RBD169. This growth inhibition might have been caused by toxicity of catechol, which has been described previously for growth of ADP1 on anthranilate (4).

benABC genes in other Rhodococcus species. In order to examine the distribution of ben gene homologs in Rhodococcus species, Southern hybridization analysis with an RHA1 ben$A B C$ probe was performed by using $K p n I$ digests of total DNAs prepared from eight rhodococcal strains, including Rhodococcus erythropolis NY05 and IAM1399 (= ATCC 15963), Rhodococcus rhodochrous IAM12121 (= ATCC 4273), IAM12123 (= ATCC 4276), and IAM12124 (= ATCC 15906), and Rhodococcus roseus ( $R$. rhodochrous) IAM12127 (= ATCC 4004), as well as $R$. erythropolis IAM12122 (= ATCC 4277) and IAM1484 (= ATCC 15961). The first six strains could convert 


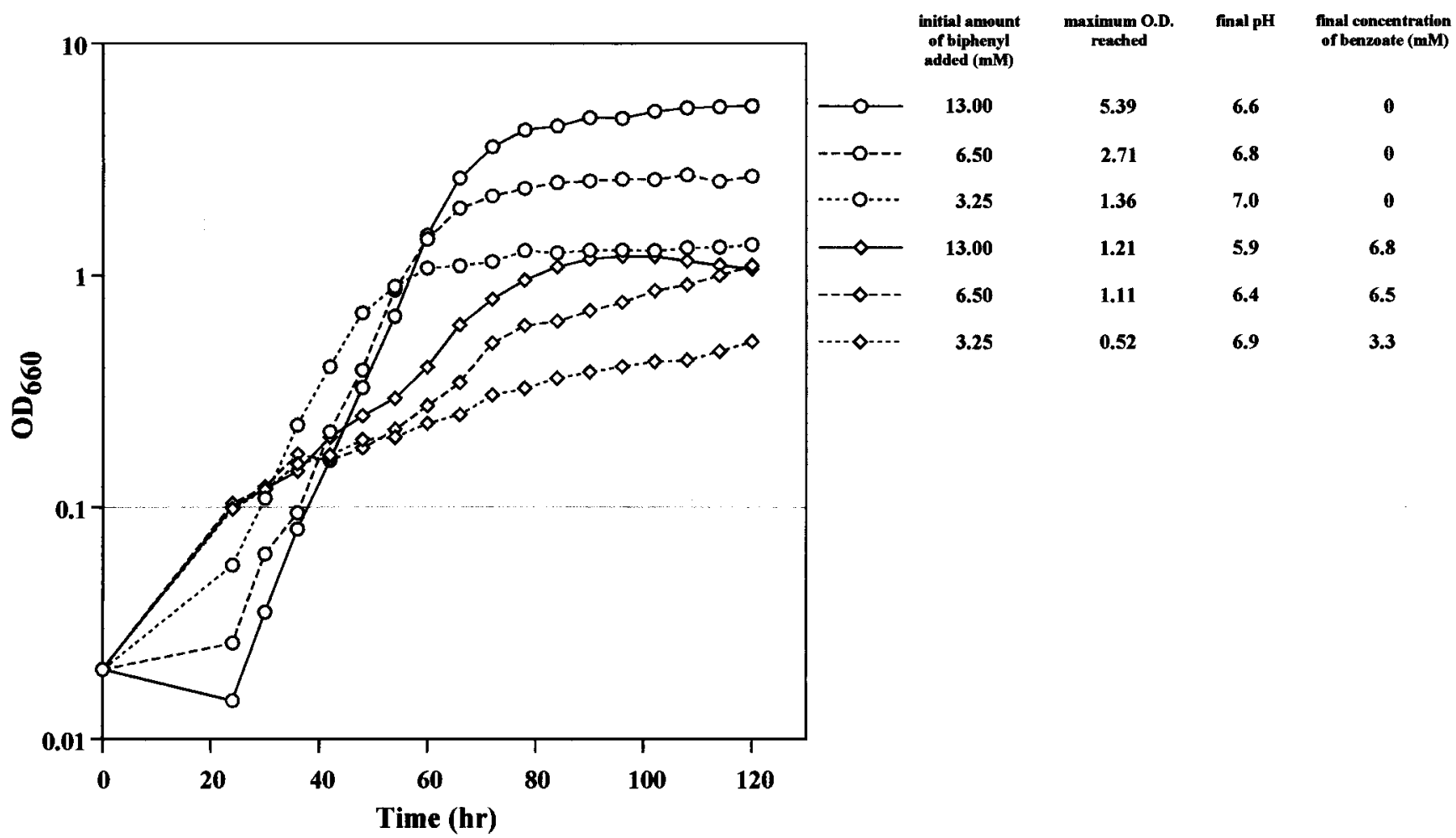

FIG. 6. Growth of RBD169 on biphenyl. RHA1 $(\bigcirc)$ and RBD169 $(\diamond)$ were grown in W minimal medium containing 3.25, 6.5 , or 13 mM biphenyl. The maximum $\mathrm{OD}_{660}$ (O.D.) values, the final $\mathrm{pH}$ values, and the final benzoate concentrations are indicated on the right. The data are averages based on triplicate experiments.

and assimilate benzoate, while the last two could not. As shown in Fig. 7, all six strains that could assimilate benzoate had ben $A B C$ homologs, but the two strains that were unable to assimilate benzoate did not. Four $R$. rhodochrous strains, IAM12121, IAM12123, IAM12124, and IAM12127, had ben$A B C$ fragments of the same size.

\section{DISCUSSION}

In the present study we characterized the benzoate catabolic genes of a gram-positive PCB degrader, Rhodococcus sp. strain RHA1, including benA, which was originally identified as an aromatic ring hydroxylation dioxygenase gene, by using PCR and temporal temperature gradient electrophoresis. The deduced amino acid sequences encoded by RHA1 benzoate catabolic genes exhibited some identity with the sequences of gram-negative bacteria. Homologs of the ADP1 benM and benE genes and the $P$. putida PRS2000 benR gene, however, were found neither $3 \mathrm{~kb}$ upstream nor $3 \mathrm{~kb}$ downstream of the benABCDK genes in RHA1. Distinctive gene organization compared to the organizations found in gram-negative bacteria was also observed for RHA1 upper biphenyl catabolic genes, including $b p h A, b p h B, b p h C$, and $b p h D$. The RHA1 benzoate catabolic genes, as well as the biphenyl catabolic genes, seem to have diverged from the genes of gram-negative bacteria at an early stage of evolution. In contrast to the upper biphenyl catabolic genes of RHA1, which are located on linear plasmids, benzoate catabolic genes were found to be localized on the chromosome. It seems reasonable that genes responsible for basic metabolic routes, such as benzoate catabolic genes, are located on a chromosome, which is more stable than plasmids. In addition to the different gene organization compared with the organization of the benzoate catabolic genes of gramnegative bacteria, RHA1 benC had an extra carboxyl-terminal sequence that was also revealed by the molecular weight of its product as estimated by SDS-PAGE analysis. This extra carboxyl-terminal sequence and its product exhibit no apparent similarity with any known nucleotide or amino acid sequence or sequence motif, and the role of the carboxyl-terminal extension is not known.

Growing cells of an E. coli recombinant strain harboring RHA1 ben $A B C$ and ben $D$ coding for benzoate dioxygenase and dihydrodiol dehydrogenase, respectively, transformed benzoate to catechol via DHB. These results indicated that the cloned ben $A B C$ and ben $D$ genes were functionally active. However, this activity was observed neither in resting cells nor in a crude cell extract. This may be explained by the instability of the gene products. Continuous synthesis of proteins in growing cells could keep providing intact gene products. Another possible explanation is a lack of $\mathrm{NADH}$, which is required to reduce an electron transfer subunit encoded by benC that activates the terminal dioxygenase component of benzoate dioxygenase encoded by ben $A B$. This explanation appears to be unlikely, however, because a crude extract of an E. coli recombinant strain showed no activity even in the presence of $\mathrm{NADH}$. The transformation competence of recombinant $E$. coli cells grown on benzoate and chlorobenzoates was similar to that of RHA1 cells, suggesting that the cloned benABC 


\section{$\begin{array}{llllllllll}M & 1 & 2 & 3 & 4 & 5 & 6 & 7 & 8 & 9\end{array}$}

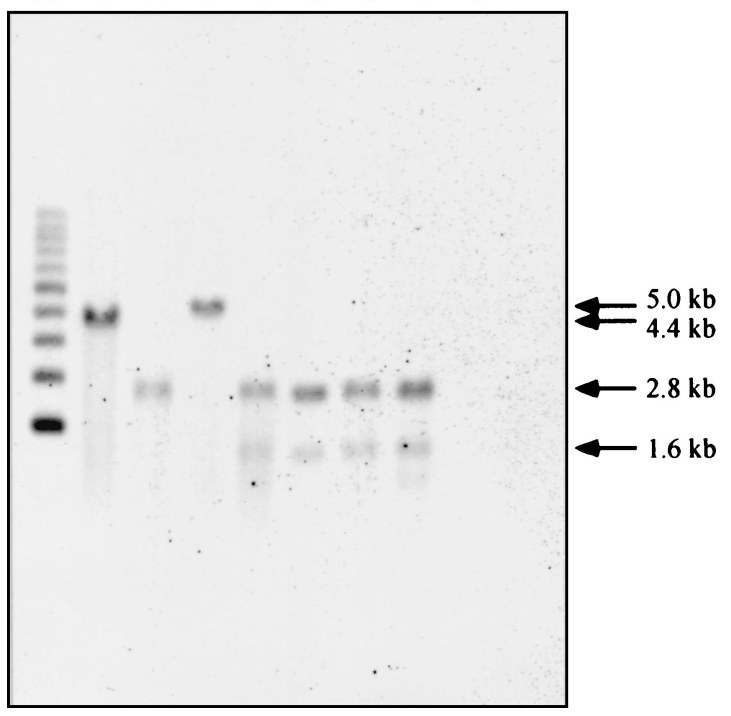

FIG. 7. Southern hybridization with RHA1 ben $A B C$ probe and KpnI-digested total DNA from Rhodococcus strains. Lane M, 1-kb molecular size ladder; lane 1, Rhodococcus sp. strain RHA1; lane 2, $R$. erythropolis NY05; lane 3, $R$. erythropolis IAM1399; lane 4, $R$. rhodochrous IAM12121; lane $5, R$. rhodochrous IAM12123; lane 6 , $R$. rhodochrous IAM12124; lane $7, R$. roseus ( $R$. rhodochrous) IAM12127; lane $8, R$. erythropolis IAM12122; lane $9, R$. erythropolis IAM1484.

genes are primarily responsible for benzoate and chlorobenzoate metabolism in RHA1. This hypothesis is supported by the results obtained with benA mutant RBD169, which transformed neither benzoate nor chlorobenzoates.

In RHA1, transcription of benA was specifically initiated both 58 and 66 bp upstream from ben $A$. This specific transcription initiation was observed only in the cells grown on benzoate, suggesting that benzoate dioxygenase activity in RHA1 is strictly regulated at the transcriptional level, as previously described for benzoate dioxygenase genes in gram-negative bacteria $(5,7,14)$. The regulated transcription from separate transcription start sites may indicate that multiple regulatory systems are involved. The $\sigma 70$ promoter consensus was identified upstream of the two transcription start sites. However, the $\sigma 70$ promoter consensus seems to be available only for the -58 minor start site, as it is too close to the -66 major start site. Except for the $\sigma 70$ promoter consensus, the proximal upstream sequence of these start sites exhibited no similarity with any known promoter consensus of bacteria, including $E$. coli and Streptomyces spp. An unknown sigma factor may be involved in transcription initiation from the -66 major start site.

We designed and constructed plasmids to insertionally inactivate the ben $A$ and ben $K$ genes only by single crossover. As reported for other strains $(3,8,26)$, homologous recombination seemed to be rare in Rhodococcus strains. This also appears to be the case in RHA1, as many of the transformants had insertions at unexpected loci other than the original locus of benA or benK. When we employed a plasmid designed to inactivate benA by double crossover, we obtained only transformants with insertions at unexpected loci (data not shown).
Gene inactivation was achieved by using the thiostrepton resistance gene. When we used a kanamycin resistance gene derived from $\operatorname{Tn} 903$, all the transformants had insertions at loci other than the original gene locus, suggesting that frequent nonhomologous illegitimate recombination had occurred. Recently, van der Geize et al. have described insertional inactivation of the $k s t D$ gene in response to the presence of a kanamycin resistance gene derived from $\operatorname{Tn} 5$ (33). The kanamycin resistance gene derived from $\operatorname{Tn} 903$ may contain a sequence that promotes illegitimate recombination.

When ben $A$ mutant RBD169 was grown on biphenyl, it accumulated benzoate originating from biphenyl. When it was grown on biphenyl at concentrations as high as $13 \mathrm{mM}$, its growth was repressed, and $6.8 \mathrm{mM}$ benzoate accumulated, indicating the importance of benzoate metabolism in degradation of biphenyl and growth on biphenyl. Because RHA1 can grow on benzoate at concentrations higher than $13 \mathrm{mM}$ when the $\mathrm{pH}$ is adjusted, low $\mathrm{pH}$ brought about by benzoate accumulation seems to be a primary cause of RBD169 growth repression. There is another possibility, that inhibition of some upper biphenyl catabolic enzyme by an accumulated product could result in growth repression. However, RBD169 grew on biphenyl in the presence of $7 \mathrm{mM}$ benzoate when the medium $\mathrm{pH}$ was adjusted to 7.0 (data not shown). Thus, this possibility seems unlikely. When the intact ben $A$ gene was introduced into RBD169, the resultant transformant, RBD169(pK4BA), grew on benzoate. Because pK4BA is a multicopy plasmid and the ben $A$ gene in pK4BA contains its original promoter region, benA gene expression in RBD169(pK4BA) should be greater than benA gene expression in RHA1. However, the growth rate of RBD169(pK4BA) on benzoate was found to be lower than that of RHA1. The difference might have been due to insertion of pDA-tsr in the benA sequence. This insertion could have decreased expression of downstream genes, including at least ben $B$ and possibly benC, benD, and benK. The reduced growth rate of RBD169(pK4BA) on benzoate might have resulted from diminished expression of these ben genes.

All of the benzoate-assimilating rhodococcal strains examined have a sequence similar to RHA1 ben $A B C$. In contrast, the two rhodococcal strains that cannot grow on benzoate do not have a sequence similar to RHA1 ben $A B C$, suggesting that genes which are very similar to RHA1 ben $A B C$ are preferentially involved in benzoate metabolism in many rhodococcal strains.

\section{ACKNOWLEDGMENT}

We thank R. van der Geize for the kind gift of plasmid pBsRG6.

\section{REFERENCES}

1. Ahmad, D., R. Massé, and M. Sylvestre. 1990. Cloning and expression of genes involved in 4-chlorobiphenyl transformation by Pseudomonas testosteroni: homology to polychlorobiphenyl degrading genes in other bacteria. Gene 86:53-61.

2. Ausubel, F. M., R. Brent, R. E. Kingston, D. D. Moore, J. G. Seidman, J. A. Smith, and K. Struhl. 1990. Current protocols in molecular biology. John Wiley \& Sons, Inc., New York, N.Y.

3. Barnes, M. R., W. A. Duetz, and P. A. Williams. 1997. A 3-(3-hydroxyphenyl) propionic acid catabolic pathway in Rhodococcus globerulus PWD1: cloning and characterization of the hpp operon. J. Bacteriol. 179:6145-6153.

4. Bundy, B. M., A. L. Campbell, and E. L. Neidle. 1998. Similarities between the ant $A B C$-encoded anthranilate dioxygenase and the ben $A B C$-encoded benzoate dioxygenase of Acinetobacter sp. strain ADP1. J. Bacteriol. 180: 4466-4474.

5. Collier, L. S., G. L. Gaines III, and E. L. Neidle. 1998. Regulation of 
benzoate degradation in Acinetobacter sp. strain ADP1 by BenM, a LysRtype transcriptional activator. J. Bacteriol. 180:2493-2501.

6. Collier, L. S., N. N. Nichols, and E. L. Neidle. 1997. benK encodes a hydrophobic permease-like protein involved in benzoate degradation by Acinetobacter sp. strain ADP1. J. Bacteriol. 179:5943-5946.

7. Cowles, C. E., N. N. Nichols, and C. S. Harwood. 2000. BenR, a XylS homologue, regulates three different pathways of aromatic acid degradation in Pseudomonas putida. J. Bacteriol. 182:6339-6346.

8. Desomer, J., M. Crespi, and M. Van Montagu. 1991. Illegitimate integration of non-replicative vectors in the genome of Rhodococcus fascians upon electrotransformation as an insertional mutagenesis system. Mol. Microbiol. 5:2115-2124.

9. Furukawa, K., and A. M. Chakrabarty. 1982. Involvement of plasmids in total degradation of chlorinated biphenyls. Appl. Environ. Microbiol. 44: 619-626.

10. Harayama, S., M. Rekik, A. Bairoch, E. L. Neidle, and L. N. Ornston. 1991. Potential DNA slippage structures acquired during evolutionary divergence of Acinetobacter calcoaceticus chromosomal ben $A B C$ and Pseudomonas putida TOL pWW0 plasmid $x y l X Y Z$, genes encoding benzoate dioxygenases. J. Bacteriol. 173:7540-7548.

11. Hashimoto, Y., M. Nishiyama, F. Yu, I. Watanabe, S. Horinouchi, and T. Beppu. 1992. Development of a host-vector system in a Rhodococcus strain and its use for expression of the cloned nitrile hydratase gene cluster. J. Gen. Microbiol. 138:1003-1010.

12. Hauschild, J. E., E. Masai, K. Sugiyama, T. Hatta, K. Kimbara, M. Fukuda, and K. Yano. 1996. Identification of an alternative 2,3-dihydroxybiphenyl 1,2-dioxygenase in Rhodococcus sp. strain RHA1 and cloning of the gene. Appl. Environ. Microbiol. 62:2940-2946.

13. Hernandez, B. S., F. K. Higson, R. Kondrat, and D. D. Focht. 1991. Metabolism of and inhibition by chlorobenzoates in Pseudomonas putida P111. Appl. Environ. Microbiol. 57:3361-3366.

14. Jeffrey, W. H., S. M. Cuskey, P. J. Chapman, S. Resnick, and R. H. Olsen. 1992. Characterization of Pseudomonas putida mutants unable to catabolize benzoate: cloning and characterization of Pseudomonas genes involved in benzoate catabolism and isolation of a chromosomal DNA fragment able to substitute for $x y l S$ in activation of the TOL lower-pathway promoter. J. Bacteriol. 174:4986-4996.

15. Kimbara, K., T. Hashimoto, M. Fukuda, T. Koana, M. Takagi, M. Oishi, and K. Yano. 1989. Cloning and sequencing of two tandem genes involved in degradation of 2,3-dihydroxybiphenyl to benzoic acid in the polychlorinated biphenyl-degrading soil bacterium Pseudomonas sp. strain KKS102. J. Bacteriol. 171:2740-2747.

16. Kitagawa, W., A. Suzuki, T. Hoaki, E. Masai, and M. Fukuda. 2001. Multiplicity of aromatic ring hydroxylation dioxygenase genes in a strong PCB degrader, Rhodococcus sp. strain RHA1, demonstrated by denaturing gradient gel electrophoresis. Biosci. Biotechnol. Biochem. 65:1907-1911.

17. Maeda, M., S. Y. Chung, E. Song, and T. Kudo. 1995. Multiple genes encoding 2,3-dihydroxybiphenyl 1,2-dioxygenase in the gram-positive polychlorinated biphenyl-degrading bacterium Rhodococcus erythropolis TA421, isolated from a termite ecosystem. Appl. Environ. Microbiol. 61:549-555.

18. Maltseva, O. V., T. V. Tsoi, J. F. Quensen III, M. Fukuda, and J. M. Tiedje. 1999. Degradation of anaerobic reductive dechlorination products of Aroclor 1242 by four aerobic bacteria. Biodegradation 10:363-371.

19. Masai, E., K. Sugiyama, N. Iwashita, S. Shimizu, J. E. Hauschild, T. Hatta, K. Kimbara, K. Yano, and M. Fukuda. 1997. The bphDEF meta-cleavage pathway genes involved in biphenyl/polychlorinated biphenyl degradation are located on a linear plasmid and separated from the initial $b p h A C B$ genes in Rhodococcus sp. strain RHA1. Gene 187:141-149.

20. Masai, E., A. Yamada, J. M. Healy, T. Hatta, K. Kimbara, M. Fukuda, and K. Yano. 1995. Characterization of biphenyl catabolic genes of gram-positive polychlorinated biphenyl degrader Rhodococcus sp. strain RHA1. Appl. Environ. Microbiol. 61:2079-2085.

21. Mondello, F. J. 1989. Cloning and expression in Escherichia coli of Pseudomonas strain LB400 genes encoding polychlorinated biphenyl degradation. J. Bacteriol. 171:1725-1732.

22. Myöhänen, S., and J. Wahlfors. 1993. Automated fluorescent primer extension. BioTechniques 14:16-17.

23. Neidle, E. L., C. Hartnett, L. N. Ornston, A. Bairoch, M. Rekik, and S. Harayama. 1991. Nucleotide sequences of the Acinetobacter calcoaceticus ben $A B C$ genes for benzoate 1,2-dioxygenase reveal evolutionary relationships among multicomponent oxygenases. J. Bacteriol. 173:5385-5395.

24. Neidle, E. L., M. K. Shapiro, and L. N. Ornston. 1987. Cloning and expression in Escherichia coli of Acinetobacter calcoaceticus genes for benzoate degradation. J. Bacteriol. 169:5496-5503.

25. Pellizari, V. H., S. Bezborodnikov, J. F. Quensen III, and J. M. Tiedje. 1996. Evaluation of strains isolated by growth on naphthalene and biphenyl for hybridization of genes to dioxygenase probes and polychlorinated biphenyldegrading ability. Appl. Environ. Microbiol. 62:2053-2058.

26. Powell, J. A., and J. A. Archer. 1998. Molecular characterisation of a Rhodococcus ohp operon. Antonie van Leeuwenhoek 74:175-188.

27. Reineke, W. 1998. Development of hybrid strains for the mineralization of chloroaromatics by patchwork assembly. Annu. Rev. Microbiol. 52:287-331.

28. Rodrigues, J. L., O. V. Maltseva, T. V. Tsoi, R. R. Helton, J. F. Quensen III, M. Fukuda, and J. M. Tiedje. 2001. Development of a Rhodococcus recombinant strain for degradation of products from anaerobic dechlorination of PCBs. Environ. Sci. Technol. 35:663-668.

29. Seto, M., K. Kimbara, M. Shimura, T. Hatta, M. Fukuda, and K. Yano. 1995. A novel transformation of polychlorinated biphenyls by Rhodococcus sp. strain RHA1. Appl. Environ. Microbiol. 61:3353-3358.

30. Seto, M., E. Masai, M. Ida, T. Hatta, K. Kimbara, M. Fukuda, and K. Yano. 1995. Multiple polychlorinated biphenyl transformation systems in the grampositive bacterium Rhodococcus sp. strain RHA1. Appl. Environ. Microbiol. 61:4510-4513.

31. Shimizu, S., H. Kobayashi, E. Masai, and M. Fukuda. 2001. Characterization of the $450-\mathrm{kb}$ linear plasmid in a polychlorinated biphenyl degrader, Rhodococcus sp. RHA1. Appl. Environ. Microbiol. 67:2021-2028.

32. Sondossi, M., M. Sylvestre, and D. Ahmad. 1992. Effects of chlorobenzoate transformation on the Pseudomonas testosteroni biphenyl and chlorobiphenyl degradation pathway. Appl. Environ. Microbiol. 58:485-495.

33. van der Geize, R., G. I. Hessels, R. van Gerwen, J. W. Vrijbloed, P. van der Meijden, and L. Dijkhuizen. 2000. Targeted disruption of the kstD gene encoding a 3-ketosteroid $\Delta^{1}$-dehydrogenase isoenzyme of Rhodococcus erythropolis strain SQ1. Appl. Environ. Microbiol. 66:2029-2036.

34. Yamada, A., H. Kishi, K. Sugiyama, T. Hatta, K. Nakamura, E. Masai, and M. Fukuda. 1998. Two nearly identical aromatic compound hydrolase genes in a strong polychlorinated biphenyl degrader, Rhodococcus sp. strain RHA1. Appl. Environ. Microbiol. 64:2006-2012.

35. Yanisch-Perron, C., J. Vieira, and J. Messing. 1985. Improved M13 phage cloning vectors and host strains: nucleotide sequences of the M13mp18 and pUC19 vectors. Gene 33:103-119. 